\title{
Dynamical Properties of Omani Crude Oils for Flow Through a Vertical Annulus and a Cylindrical Pipe
}

\author{
Sayyadul Arafin* and S.M. Mujibur Rahman
}

Department of Physics, College of Science, Sultan Qaboos University, P.O.Box 36, Al-Khoud, 123 Muscat, Sultanate of Oman, *Email: sayfin@squ.edu.om.

$$
\text { الخواص الديناميكية للنفط العماني الخام عند سريانه عبر أنبوب حلقي أو أسطواني }
$$

ملخص: قمنا في بداية هذه الدراسة بالتحقيق في مدى اعنماد الكثافة و اللزوجة على دئ درجة الحرارة لعينات من النفط الخام

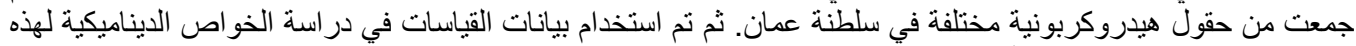

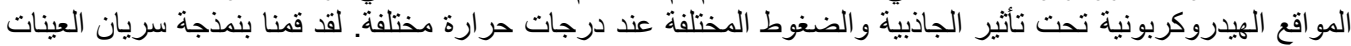

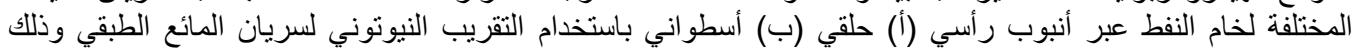

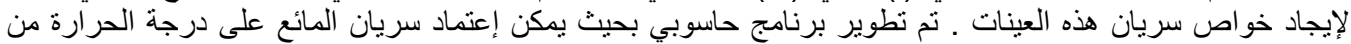

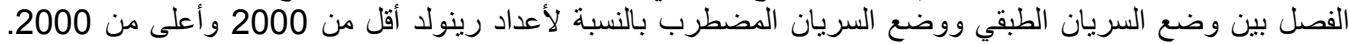

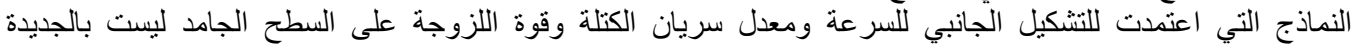

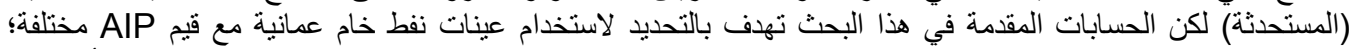

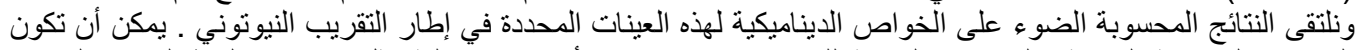

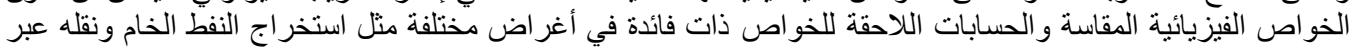

ABSTRACT: We have initially investigated the temperature dependence of density and viscosity of a number of crude oils, collected from various hydrocarbon reservoirs in Oman. The measured data are then utilized to investigate the flow dynamics of these hydrocarbon fluids under gravity and applied pressures at various temperatures. We have modeled the flow of the various crude oil samples through a vertical (a) annulus and (b) cylindrical pipe - all treated within the Newtonian fluid flow approximation of a laminar flow - to investigate the flow properties of these samples. A computer program is developed so that the temperature dependence of the fluid flow distinctly separates the laminar mode from a turbulent mode with respect to Reynolds numbers within the ranges $\operatorname{Re}<2000$ and $\mathrm{Re}>2000$. The adopted models of the velocity profiles, mass rate of flow and viscous force on the solid surface are not novel, but the present calculations aim to specifically use the various Omani crude oil samples with various AIP values; the calculated results shed some light on the dynamics of these specific samples within Newtonian approximation. The measured physical properties and the subsequent calculations of the relevant dynamical properties might be useful for various purposes e.g. extraction and transportation of crude oils through pipes.

KEYWORDS: Dynamics; Flow properties; Hydrocarbon fluids; Cylinder and annulus. 


\section{DYNAMICAL PROPERTIES OF OMANI CRUDE OILS}

\section{Introduction}

$\mathbf{T}$

emperature dependence of thermo-physical properties, e.g., densities and viscosities of hydrocarbon fluids plays an important role in many fields of petroleum industries including enhanced oil recovery, oil purification, and transportation of produced fluids (Ahmed, 2000). When producing heavy oils, the high viscosity manifests as one of the impediments to recovering these oils from the oil rigs. The temperature dependence of the transport properties influences the relevant flow dynamics, which in turn affect the flow mechanism (Li et al. 2004). We present here a model study of the temperature dependence of certain dynamic properties such as velocity distribution, mass rate of flow and viscous force on the solid surface through a vertical annulus and a cylinder.

The present investigation primarily aims at understanding the profile of a number of dynamic properties of Omani crude oils through a vertical annulus at various temperatures and applied pressures. We may mention that fluid flow through an annulus has wide applications in various branches of science and technology including nuclear reactor engineering, oil and gas production, aero-engines, turbo-machinery, chemical engineering, steam generators and heat exchangers. Knowledge of the dynamics of energy flows either in the form of heat transfer or fluid flows through a vertical annulus or normal cylinder under atmospheric and pressurized conditions, can help us understand the re-flooding phenomenon during the emergency cooling in a water-cooled reactor (Shiotsu and Hama, 2000). It is particularly important in the petroleum industry because annular flow of liquid and gas in a pipeline segregates the material of lighter molecular weight by restricting its flow down the center of the pipe while allowing the material of heavier molecular weight to form a thin film and flow along the pipe wall. The lighter mass fluid or gas can also be in the form of a mist or colloidal suspension known as an emulsion. The interface between the flowing materials may not be entirely precise, and can involve gas and liquid mixtures. It has been suggested (Prada and Bannwart, 2001) that the use of a core-annular flow pattern may be made attractive as an artificial lift method in heavy oil wells by inducing the flow pattern by the lateral injection of relatively small quantities of water in order to get a lubricated oil core along the pipe. Concurrently we have also investigated the flow properties of a number of Omani crude oil samples through a vertical cylinder. The research work on vertical upward core flow is nonetheless scanty; particularly, the theme of research on flow dynamics with Omani crudes is novel and in its infancy (Arafin et al. 2011). However, the works of Shertok (1975), Bai et al. (1996) and, Ho and Li (1994) on various samples are worth mentioning here.

The prime interest in annular flow is to study the parameters relevant to the transport of fluids through straight pipes whether horizontal or vertical. However, presently, interest in annular flow goes beyond straight pipes to include intersections in pipe line networks, such as T-junctions, where phase segregation is likely to exist (Adechy and Issa, 2004).

We have used here the Newtonian fluid approximation relevant only to laminar and linear fluids flows. Certainly crude oils are far from Newtonian fluids. It is relevant to mention here that the Newtonian approximation is highly limited to homogeneous, isotropic and non-compressible systems where stress-velocity gradient relations are non-linear. Above all, any non-Newtonian fluid has a non-zero term on the right hand side of the momentum-balance equation. Consideration of non-Newtonian approximation will certainly necessitate the non-linear form of the Navier-Stokes equation. Thus it is apparent that the present approximation yields qualitative results only.

Thus for a non-laminar and nonlinear case, the situation will be certainly complex, and that will be considered in a future endeavor. In the present investigation, initially, the densities of the samples were measured by using the Anton Paar density meter (DMA 5000) within temperatures from $20^{\circ} \mathrm{C}$ to $70^{\circ} \mathrm{C}$, at steps of $5^{\circ} \mathrm{C}$.

Subsequently, the kinematic and dynamic viscosities for all the samples were measured within this range of temperatures using a state-of-the-art Cannon-Fenske viscometer. Finally, the density and viscosity data were utilized to calculate the velocity distribution, maximum and average velocities of the bulk samples, and their mass flow rate under various thermal conditions. The calculations were constrained by prefixing the Reynolds number, $R e$, at 2000, ensuring a laminar flow as suggested by Bird et al. (2002). 


\section{SAYYADUL ARAFIN and S.M. MUJIBUR RAHMAN.}

The layout of the paper is as follows: In Section 2 we describe the experimental details for measuring the densities and viscosities of the samples followed by a display of graphical results for temperature dependence of density and viscosity, and we end with fitting formulas. Basic model-based formulation for the dynamical quantities is presented in Section 3. Details of calculated results are presented and discussed in Section 4 followed by some concluding remarks in Section 5 .

\section{Experimental measurements}

In this section, we describe the experimental details of measuring the densities and viscosities at various temperatures for all the five samples.

\subsection{Density measurements at various temperatures}

We briefly introduce here the classification of the crude oil samples that were procured from different oil fields in Oman. The two samples (Oman Export and Receive Line) comprising mixtures of crude oils were collected from the Petroleum Development of Oman (PDO). The other three samples were collected from Erad field, Mabruk field, and Zal-41 field located in different regions in Oman. We have used the American Petroleum Institute (API) oil gravity number to classify our oil samples:

$$
A P I=\frac{141.5}{\rho_{0}-131.54}
$$

Here, $\rho_{0}$ is the density $\left(\mathrm{g} \mathrm{cm}^{-3}\right)$ measured at temperature $15.6^{\circ} \mathrm{C}$ and at atmospheric pressure. The API numbers usually vary from 5 for very heavy oils to nearly 100 for light condensates (Batzle and Wang, 1992). Clearly, our samples may be classified into three types. The heavy type is represented by the Erad (API=19.19) sample; to the intermediate type belong the Oman Export $(A P I=33.41)$ and Receive Line samples $(\mathrm{API}=34.13)$, while the light type consists of Mabruk $(A P I=39.47)$ and Zal-41 $(A P I=40.89)$ samples.

The densities of the samples were measured by using the Anton Paar density meter (DMA5000) as shown in Figure 1. The unit consists of a U-shaped oscillating tube, a system for electronic excitation, frequency counting, and a display. The injected sample volume is kept constant and vibrated. The density is calculated based on a measurement of the sample oscillation period and temperature. The temperature was controlled to \pm $0.01{ }^{\circ} \mathrm{C}$ during the measurement using a built-in thermostat. By measuring the damping of the U-tube's oscillation caused by the viscosity of the filled-in sample, the instrument automatically corrects the viscosityrelated errors. The Anton Paar density meter is calibrated to measure density to an accuracy of $\pm 5 \times 10^{-3} \mathrm{~kg} \mathrm{~m}^{-3}$. This device was used to measure the density in the range of temperature varying from $20^{\circ} \mathrm{C}$ to $70^{\circ} \mathrm{C}$, through temperature increments of $5^{\circ} \mathrm{C}$.

From the practical point of view, density data of crude oil as a function of temperature provide important information, which is useful for various industrial applications ranging from exploration to refining and transportation. The density data of crude oil were plotted in Figure 2. These data can be adequately represented by the equation:

$$
\rho(T)=\rho_{r}+m\left(T-T_{r}\right)
$$

where $\rho_{r}$ is the density at $20^{\circ} \mathrm{C}, m$ is the slope of the density versus temperature curve $(\mathrm{d} \rho / d T), T$ is the temperature $\left({ }^{\circ} \mathrm{C}\right)$, and $T_{\mathrm{r}}$ is the room temperature $\left(20^{\circ} \mathrm{C}\right)$. 


\section{DYNAMICAL PROPERTIES OF OMANI CRUDE OILS}

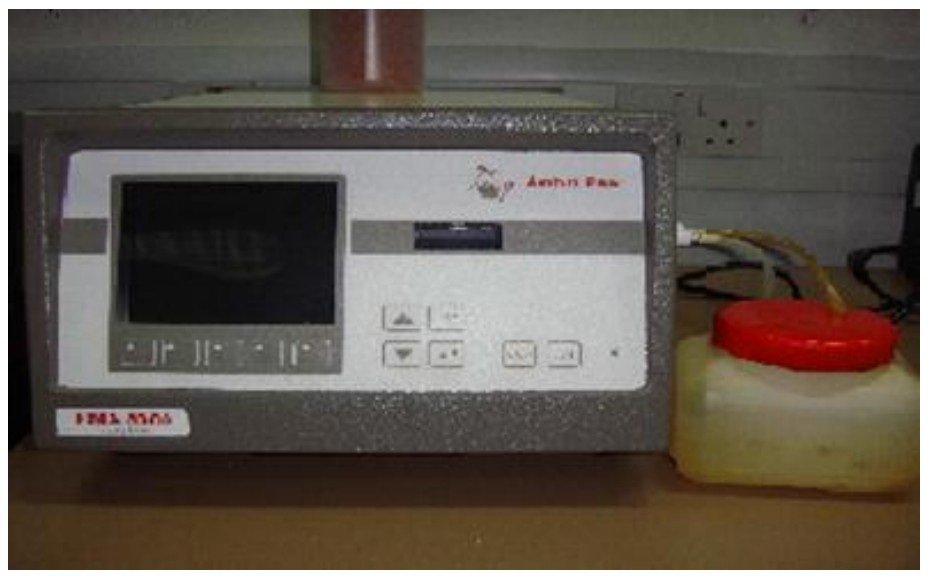

Figure 1. Anton Paar density meter (DMA 5000).

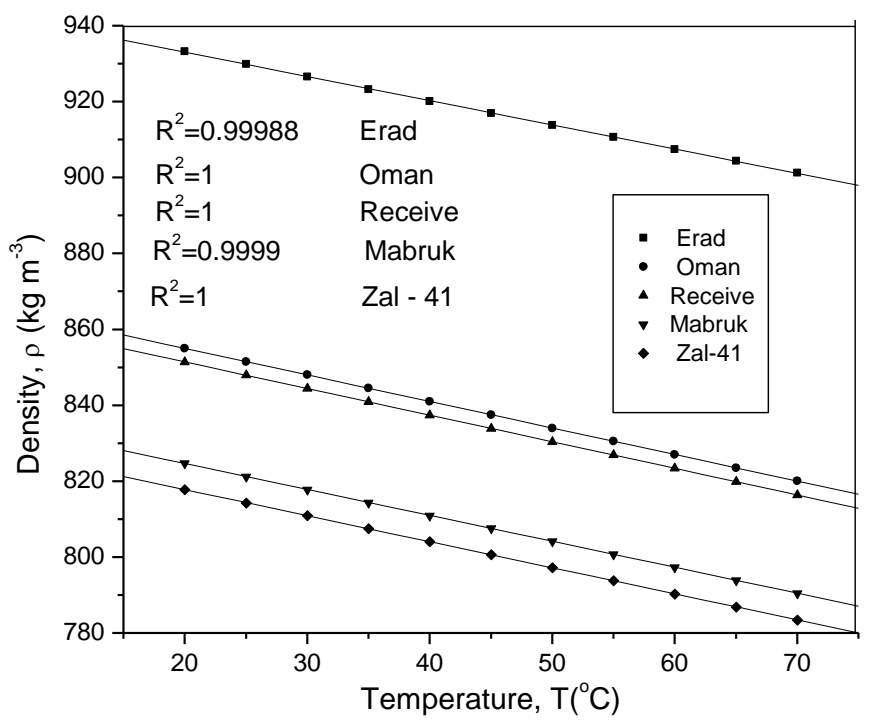

Figure 2. Density versus temperature for various collected crude oils.

The error in density, $\Delta \rho$, is $0.005 \mathrm{~kg} \mathrm{~m}^{-3}$. The equations for density as a function of temperature obtained by a fitting procedure are written in the form of Eq. 2 as follows:

Erad sample:

Oman Export sample:

Receive Line sample:

Mabruk sample:

Zal_41 sample:

$$
\begin{aligned}
& \rho(T)=933.008-0.638\left(T-T_{r}\right) \\
& \rho(T)=868.980-0.699\left(T-T_{r}\right) \\
& \rho(T)=851.426-0.701\left(T-T_{r}\right) \\
& \rho(T)=824.645-0.683\left(T-T_{r}\right) \\
& \rho(T)=817.772-0.686\left(T-T_{r}\right)
\end{aligned}
$$




\section{SAYYADUL ARAFIN and S.M. MUJIBUR RAHMAN.}

\subsection{Viscosity measurements at various temperatures}

Two types of Cannon-Fenske viscometers, type 350 and 300 with calibration constant $5 \times 10^{-6} \mathrm{~m}^{2} \mathrm{~s}^{-1}$ and $2.5 \times 10^{-6} \mathrm{~m}^{2} \mathrm{~s}^{-1}$ respectively, were used to measure the viscosity. A Cannon-Fenske viscometer type 350, was used to measure viscosity of the Erad sample, the heaviest crude among the five samples. For the rest of the crude oil samples, a Cannon-Fenske viscometer type 300 was used. The working principle of the viscometer is based on the fact that the average velocity of steady flow in a round tube depends inversely on viscosity. The viscometer determines the kinematic viscosity by timing the fluid flow through a capillary tube as it passes between two etched lines on the glass wall. In our experiment, the viscometer was inserted into a constant temperature bath whose temperature was controlled to $\pm 0.1^{\circ} \mathrm{C}$ using a Haake $D 8$ circulation thermostat. To establish the efflux time, the thermostat was set at a desired temperature and the sample liquid was allowed to fall freely down past an upper mark and the time taken for the meniscus to pass the lower mark was measured. The kinematic viscosity $\left(v_{\mathrm{k}}\right)$ was determined by multiplying the measured transit time of the fluid column in seconds with the calibration constant. The error of the viscosity measurement is $<0.35 \%$. The error in the measurement of viscosity is too small to be shown in the plot (Figure 3a-b).

From the Figures $3 \mathrm{a}$ and $3 \mathrm{~b}$, it is clear that the kinematic viscosity decreases exponentially (Arrhenius type) as the temperature increases; this correctly reflects the effect of temperature on the crude oil viscosity. From the plot, it is also evident that crude oil samples with lower API values have higher kinematic viscosity. An identical behavior of the viscosities of various Omani crude oils has been reported previously (George et al. 2006).

The equations of kinematic viscosity as a function of temperature were obtained by exponential fit of the data of various crude oil samples. These are listed as follows:

$$
\begin{array}{ll}
\text { Erad: } & v_{k}(T)=106.12+21384.40 e^{(-T / 11.98)} \\
\text { Oman Export: } & v_{k}(T)=3.21+47.46 e^{(-T / 23.72)} \\
\text { Receive Line: } & v_{k}(T)=4.66+36.44 e^{(-T / 23.88)} \\
\text { Mabruk: } & v_{k}(T)=3.27+26.70 e^{(-T / 17.95)} \\
\text { Zal-41: } & v_{k}(T)=2.05+16.19 e^{(-T / 28.6)}
\end{array}
$$

The dynamic viscosity, $\mu(\mathrm{Pa} \mathrm{s})$, is determined from the product of kinematic viscosity, $v$, and density, $\rho(\mu=v \rho)$. It is noted that the viscosity of a fluid is highly temperature-dependent. The viscosity of the crude oil decreases exponentially as the temperature increases from $20^{\circ} \mathrm{C}$ to $70^{\circ} \mathrm{C}$. The present results are consistent with the correlation approach (Naseri et al. 2005) for prediction of crude oil viscosity.

\section{Formulation}

The present study applies only to steady-state flow relevant to Newtonian fluids. By steady state flow it is understood that the flow conditions at each point in the stream do not change with time. For this approximation, the momentum balance equation is (Bird et al. 2002):

$$
\frac{d p_{\text {in }}}{d t}-\frac{d p_{\text {out }}}{d t}+\sum_{j} F_{j}=0
$$

where $p_{\text {in }}$ and $p_{\text {out }}$ are the momentum entering into and going out of the system respectively. $\Sigma F_{j}$ is the sum of the forces acting on the system. As shown in Figure 4, we focus our attention on a region of length $L$, 


\section{DYNAMICAL PROPERTIES OF OMANI CRUDE OILS}

sufficiently far from the ends of the wall so that the entrance and exit disturbances are not included in $L$. This ensures that in this region the velocity component $V_{z}$ does not depend on $z$.

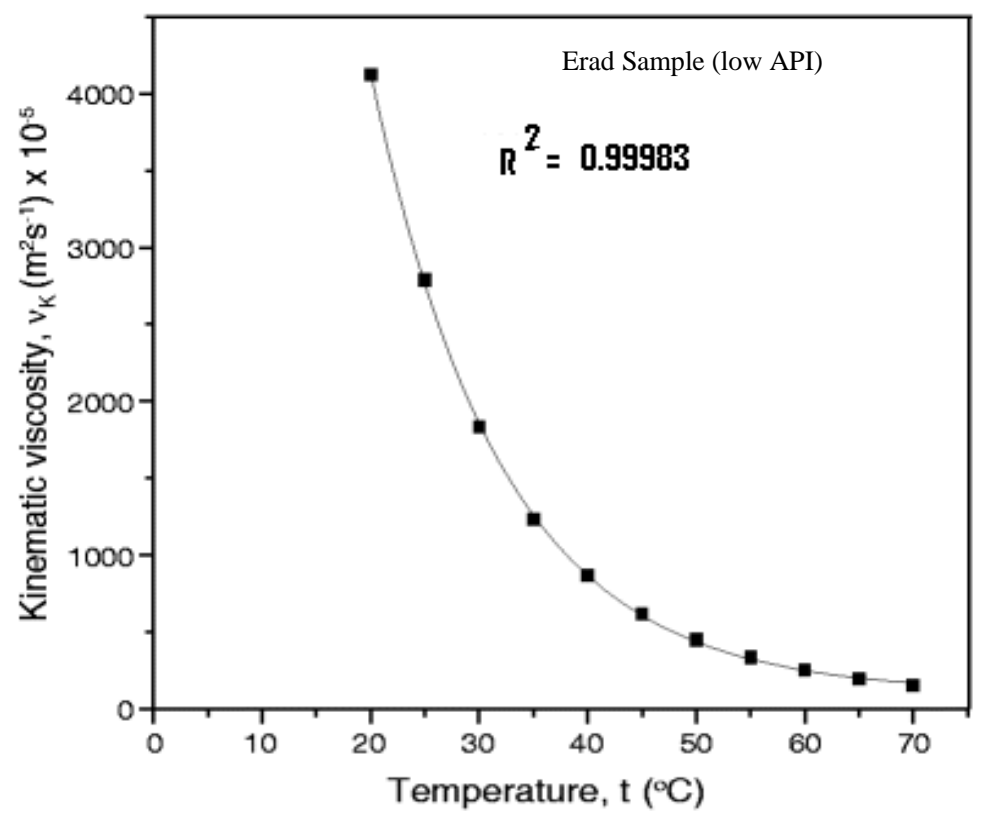

(a)

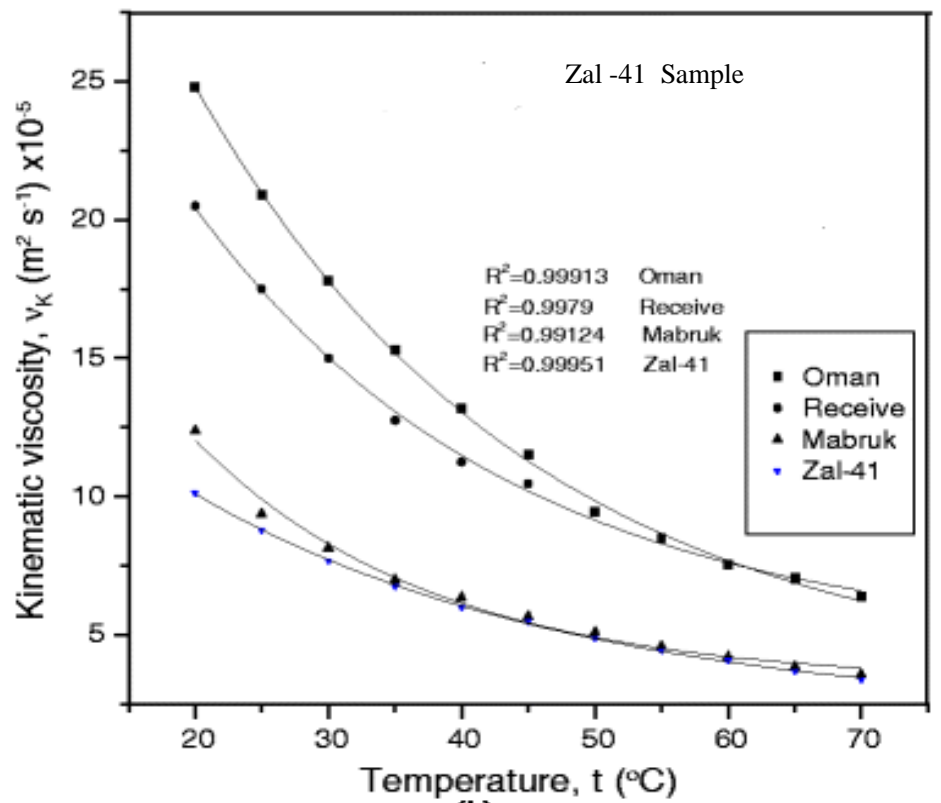

(b)

Figure 3. Kinematic viscosity versus temperature for the: (3a) Erad sample and (3b) Oman Export, Receive Line, Mabruk, and Zal-41 samples. 


\section{SAYYADUL ARAFIN and S.M. MUJIBUR RAHMAN.}

\subsection{Flow through a vertical annulus}

The flow of fluids in an annulus (Figure 4) is encountered frequently in physics, chemistry, biology, and engineering. The laminar flow of fluid in an annulus may be analyzed by means of momentum balance described in the previous section. By considering an incompressible fluid flowing in steady state in the annular region between two coaxial circular cylinders of radii $\kappa R$ and $R$ (Figure 4), the equation for velocity profile of Bird et al. (2002) can be written with slight rearrangement in the form:

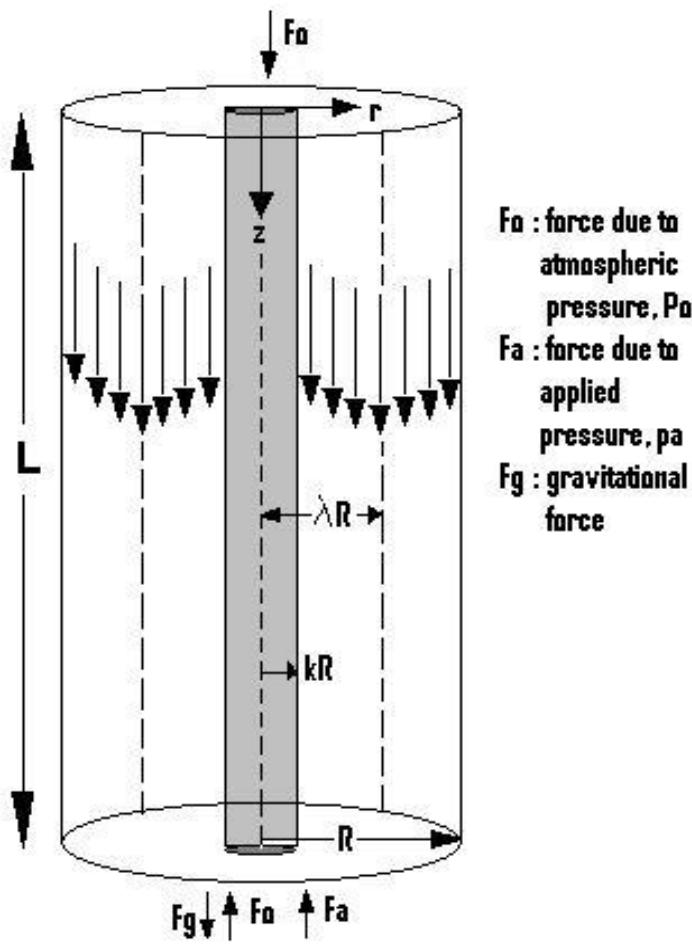

Figure 4. Flow through an annulus. The various forces acting on the top and bottom surface of the annulus.

$$
v_{z}=\frac{\left(P_{0}-P_{L}\right) R_{\text {out }}^{2}}{4 \mu L}\left[1-\left(\frac{r}{R_{\text {out }}}\right)^{2}-\left(\frac{1-\kappa^{2}}{\ln \kappa}\right) \ln \left(\frac{r}{R_{\text {out }}}\right)\right]
$$

where $\kappa$ is the ratio of the inner to the outer radius $\left(\kappa=\mathrm{r}_{i n} / R_{\text {out }}\right), P_{o}$ is the atmospheric pressure, and $r$ is the distance measured from the outer surface of the inner cylinder to the inner surface of the outer cylinder. The quantity $P_{L}$ represents the combined effect of pressure, $p_{L}$ and the gravitational term $(\rho g L) . \mu$ and $\rho$ are viscosity and density of the fluid respectively. With the help of figure 4 it can be shown that the term $\left(P_{0}-P_{L}\right)$ is the net pressure, $\Delta P$ which can be replaced by $\Delta P=\Delta p=p_{\mathrm{a}^{-}} \rho g L$. $p_{\mathrm{a}}$ is the applied pressure as shown in figure 4. Since $\rho$ is a function of temperature, the net pressure, $\Delta p$, is a function of temperature as well. The fluid will remain static if the net pressure is equal to zero, which means that the applied pressure, $p_{a}$ at the bottom of the annulus will exactly balance $\rho g L$. Since our prime objective is to determine the temperature dependence of flow 


\section{DYNAMICAL PROPERTIES OF OMANI CRUDE OILS}

properties we express all the relevant equations as a function of temperature through the temperature dependence of $\mu$ and $\rho$. Therefore Eq. 6 can be written in terms of net pressure as:

$$
v_{z}(r, T)=\frac{\Delta p R_{\text {out }}^{2}}{4 \mu L}\left[1-\left(\frac{r}{R_{\text {out }}}\right)^{2}-\left(\frac{1-\kappa^{2}}{\ln \kappa}\right) \ln \left(\frac{r}{R_{\text {out }}}\right)\right]
$$

The second term in the square bracket may be termed as the pipe characteristic function, which at any point along $r$ depends solely on the pipe dimension.

Eq. 7 works only under the conditions that (i) the fluid is of constant density $\rho$ (incompressible), (ii) the flow is laminar, (iii) the annulus length $(L)$ is very large and (iv) there are no end effects. In fact, at the tube entrance and exit, the flow will not necessarily be parallel everywhere, so the tube surface effect will be ignored (Bird et al. 2002).

Since, we need to know the maximum velocity, the average velocity and the shear stress at a surface we have to know the range of the applied pressure for the flow to be in laminar at a given radius, length, viscosity and density. In this study we have assumed the flow to be laminar by restricting the Reynolds number, $R e$ to 2000 and constraining Re by the equation (Bird et al. 2002):

$$
\operatorname{Re}=2 R_{\text {out }}(1-\kappa)\left\langle v_{z}\right\rangle \frac{\rho}{\mu}
$$

where, $\left\langle v_{z}\right\rangle$ is the average velocity of the velocity profile, $v_{z}$ given by:

$$
\left\langle v_{z}(T)\right\rangle=\frac{\Delta p(T) R_{\text {out }}^{2}}{8 \mu(T) L} B
$$

$B$ may be termed the annular constant. It is obtained from the expression:

$$
B=\left[\left(1+\kappa^{2}\right)+\frac{\left(1-\kappa^{2}\right)}{\ln \kappa}\right]
$$

Combining equations (8) and (9) it can be shown that:

$$
\Delta p(T)=\frac{4 L \operatorname{Re}}{R_{\text {out }}^{3} B(1-\kappa)} \frac{\mu^{2}(T)}{\rho(T)}
$$

Because $\mu^{2}(T)$ decreases more rapidly with increasing temperature than $\rho$ does, $\Delta p$ will therefore decrease with increasing temperature. Substituting Eq. 11 in Eq. 7 and Eq. 9, the expressions for $v_{z}$ and $\left\langle v_{z}\right\rangle$ in terms of Reynolds number, $R e$, reduce respectively to:

$$
v_{z}(r, T)=\frac{\operatorname{Re} \mu(T)}{R_{\text {out }} \rho(T)(1-\kappa) B}\left[1-\left(\frac{r}{R_{\text {out }}}\right)^{2}-\frac{\left(1-\kappa^{2}\right)}{\ln \kappa} \ln \left(\frac{r}{R_{\text {out }}}\right)\right]
$$




\section{SAYYADUL ARAFIN and S.M. MUJIBUR RAHMAN.}

$$
\text { with }\left\langle v_{z}(T)\right\rangle=\frac{\mu(T)}{\rho(T)} \frac{\operatorname{Re}}{2 R_{\text {out }}(1-\kappa)}
$$

Both $v_{z}$ and $\left\langle v_{z}\right\rangle$ will decrease with increasing temperature because the viscosity decreases more rapidly with increasing temperature than density. Although $R e$ depends on temperature through $\rho$ and $\mu$, as suggested by Eq. 8, we have kept it fixed at 2000 for all temperatures. This will force the average velocity to adjust according to Eq. 8. By doing so no generality is lost with regard to the condition for laminar flow. This strategy makes the computation simple and less cumbersome. The mass rate of flow, $w$ is given by (Bird et al. 2002):

$$
w(T)=\pi R_{\text {out }}^{2}\left(1-\kappa^{2}\right) \rho(T)\left\langle v_{z}(T)\right\rangle
$$

Substituting Eq. 13 in Eq. 14 one can get:

$$
w(T)=\frac{\pi R_{\text {out }}(1+\kappa) \mu(T) \operatorname{Re}}{2}
$$

Again, the mass rate of flow, $w$ will decrease with increasing temperature because of the presence of $\mu$ in the numerator of Eq. 14. By keeping Re fixed at 2000, the net pressure, $\Delta p, v_{z},\left\langle v_{z}\right\rangle$ and $w$ have been calculated from Eq. 10, Eq. 11, Eq. 12 and Eq. 14 respectively as a function of temperature, $T$. The viscous force exerted by the fluid on the walls of the annulus, $F_{z}$, is given by (Bird et al. 2002):

$$
F_{z}(T)=\pi R_{\text {out }}^{2}\left(1-\kappa^{2}\right) \Delta p(T)
$$

Since $\Delta p$ decreases sharply with temperature (Eq. 11) at a fixed $R e, F_{\mathrm{z}}$ is expected to decrease with increasing temperature sharply as well.

\subsection{Flow through a vertical cylinder}

The equation of the velocity profile, $v_{z}$ obtained for a laminar flow through a cylindrical tube (Bird et al. 2002) is expressed as:

$$
v_{z}(r)=\frac{\left(P_{o}-P_{L}\right) R^{2}}{4 \mu L}\left[1-\left(\frac{r}{R}\right)^{2}\right]
$$

where $R$ is the radius of the cylinder. The variable $r$ is the distance measured from the center to the inner wall of the cylinder. The temperature dependence of $v_{z}$ for a cylinder is:

$$
v_{z}(r, T)=\left[\frac{\Delta p(T)}{\mu(T)}\right]\left[\frac{R^{2}}{4 L}\left\{1-\left(\frac{r}{R}\right)^{2}\right\}\right]
$$

where $\Delta p=\left(P_{0}-P_{L}\right)=\left[p_{a}-\rho(T) g L\right]$. The Reynolds number, Re for the flow in a cylinder is given (Bird $e t$ al. 2002) by the equation:

$$
\operatorname{Re}(T)=2 R\left\langle v_{z}(T)\right\rangle \frac{\rho(T)}{\mu(T)}
$$




\section{DYNAMICAL PROPERTIES OF OMANI CRUDE OILS}

$$
\text { with, }\left\langle v_{z}(T)\right\rangle=\frac{\Delta p(T) R^{2}}{8 \mu(T) L}
$$

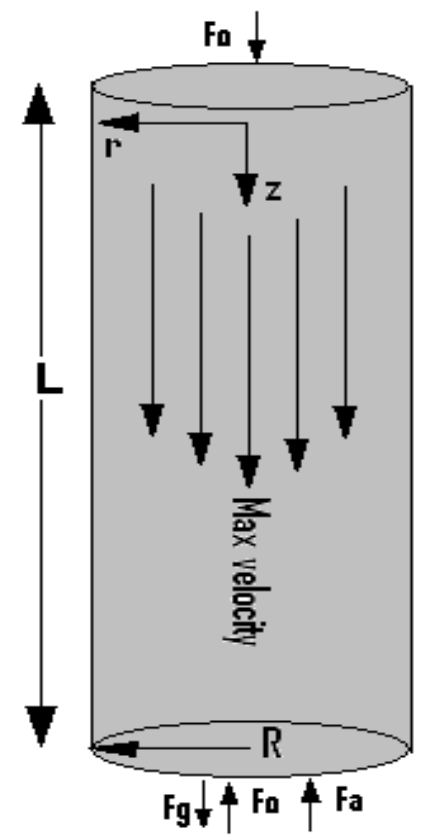

Fo : force due to atmospheric pressure. Po

Fa : force due to applied pressure, pa

Fg : gravitational force

Figure 5. Flow in a vertical cylinder of length $L$ and radius $R$. The various forces acting on the top and bottom faces of the cylinder are shown by arrows.

As in the case of annular flow, we have kept the Reynolds number, Re, fixed at 2000 for the study of laminar flow in a cylinder as well. Following the same derivation procedure as in an annulus, one can show, in terms of $R e$, that the net pressure, $\Delta p$, average velocity, $\left\langle v_{z}\right\rangle$ and velocity profile, $v_{z}$, for a cylinder can be written as:

$$
\begin{gathered}
\Delta p(T)=\frac{4 \operatorname{Re} L}{R^{3}} \frac{\mu^{2}(T)}{\rho(T)} \\
\left\langle v_{z}(T)\right\rangle=\frac{\mu(T)}{\rho(T)} \frac{\operatorname{Re}}{2 R} \\
\text { and } \quad v_{z}(T)=\frac{\operatorname{Re} \mu(T)}{R \rho(T)}\left[1-\left(\frac{r}{R}\right)^{2}\right]
\end{gathered}
$$

And, finally the mass rate of flow, $w(T)=\frac{\pi\left[p_{a}-\rho(T) g L\right] R^{4} \rho(T)}{8 \mu(T) L}$ can be expressed as 


\section{SAYYADUL ARAFIN and S.M. MUJIBUR RAHMAN.}

$$
w(T)=\frac{\pi R \operatorname{Re}}{2} \mu(T)
$$

The viscous force exerted by the fluid on the wall of the cylinder, $F_{z}$, is given by (Bird et al. 2002):

$$
F_{z}(T)=\pi R^{2} \Delta p(T)
$$

As in the case of an annulus, $F_{\mathrm{z}}$ will decrease with increasing temperature in a similar fashion.

\section{Results and discussions}

\subsection{Vertical annulus}

The calculated results on dynamical properties of the two extreme samples, namely Zal-41 [lightest] and Erad [heaviest] samples through an annulus are presented and discussed in this section. The outer radius $\left(R_{\text {out }}\right)$ and inner radius $\left(R_{\text {in }}\right)$ of the annulus are $0.5 \mathrm{~m}$ and $0.1 \mathrm{~m}$ respectively $\left(\mathrm{r}_{\mathrm{in}} / R_{\text {out }}=\kappa=0.2\right)$ and length, $L=50 \mathrm{~m}$.

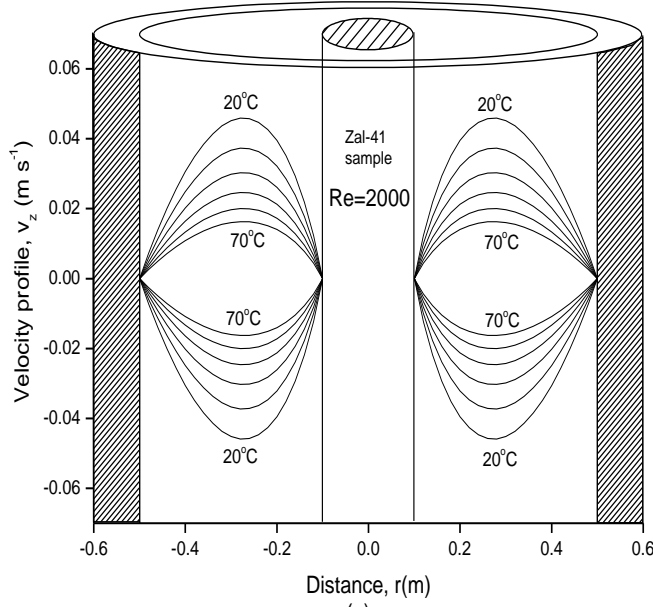

(a)

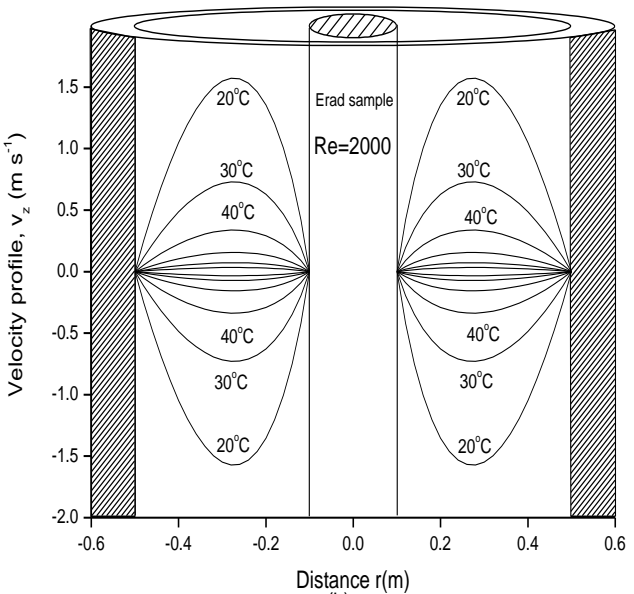

(b)

Figure 6. The velocity profiles for the (6a) flow of light (Zal-41 sample) and (6b) heavy (Erad sample) crude oils through an annulus at various temperatures.

Since the velocities [Eqs.7 and 9] within the bulk of the fluid depend on the viscosity $\mu(T)$, which decreases as the temperature increases, it seems that the profile of $v_{z}(T)$ as shown in Figure 6 is in contradiction with these equations. But the infused constraint owing to using a fixed Reynolds number $R e=2000$ in Eq. 12 and Eq. 13, turns back the velocity profile; this is now reflected by the joint effect of $\mu(T) / \rho(T)$ which essentially decreases with temperature. 


\section{DYNAMICAL PROPERTIES OF OMANI CRUDE OILS}

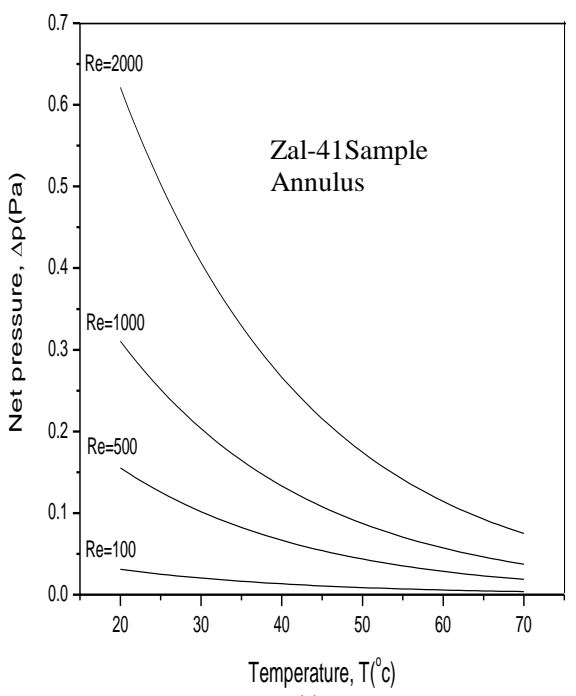

(a)

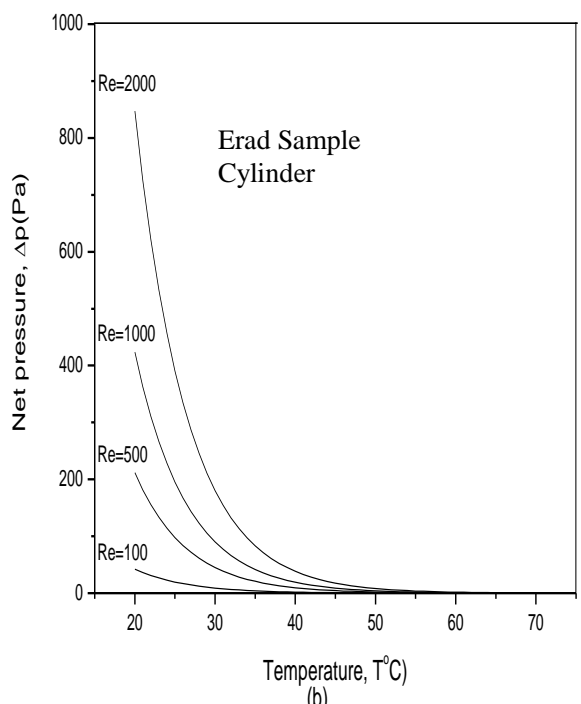

(b)

Figure 7. The net pressure as function of temperature at various Reynolds numbers, Re for (7a) Zal-41 sample and (7b) Erad sample.

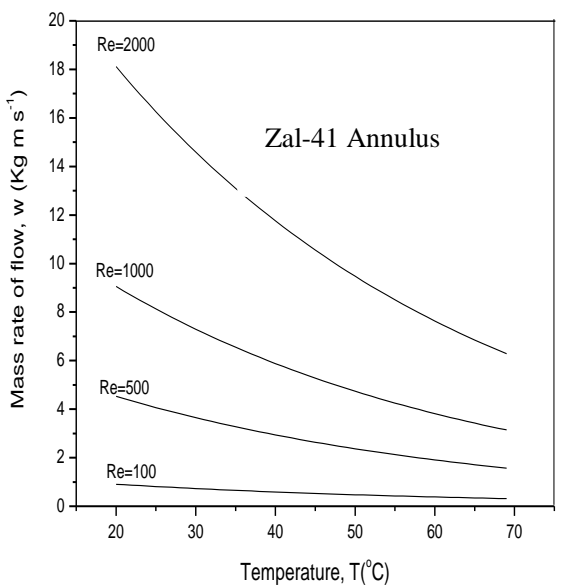

(a)

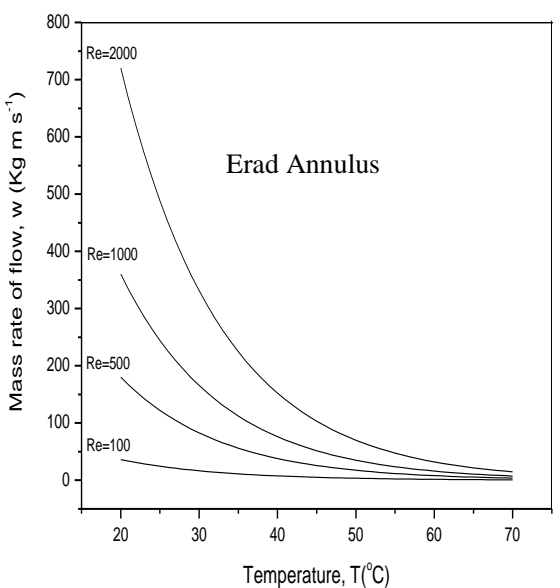

(b)

Figure 8. The mass rate of flow $w$ through an annulus as a function of temperature at various Reynolds number, $R e$, values for (8a) light (Zal-41) and (8b) heavy (Erad) crude oils.

The profile of the curves in Figure7 can be explained in terms of Eq. 11 which clearly demonstrates that for a fixed Reynolds number $R e$, the net pressure $\Delta p(T)$ will decay because of the presence of the factor $\mu^{2}(T) / \rho(T)$ which decreases as $T$ increases keeping also in mind that $\mu(T)$ decreases more rapidly than $\rho(T)$. The rapid increase of viscosity values at the limit of the low temperature range is also truly reflected 


\section{SAYYADUL ARAFIN and S.M. MUJIBUR RAHMAN.}

accordingly in the $\Delta p(T)$ curves in the figure. Concurrently it is also relevant to mention that the results ideally reflect the varying viscous nature of the lightest (Zal-41) and heaviest (Erad) samples through a rapid variation of the profile of $\Delta p(T)$ at this limit.

The profiles of $\Delta p(T)$ and $w(T)$ display some similar features; this is primarily because of the presence of the viscosity at the numerators in Eq. 11 and Eq. 15.

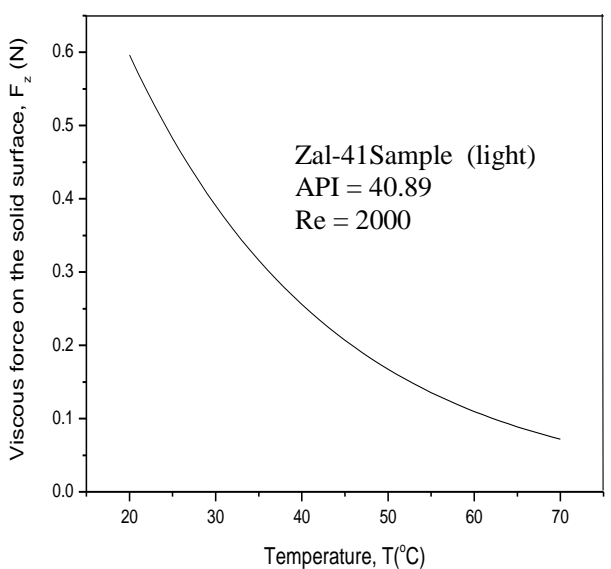

(a)

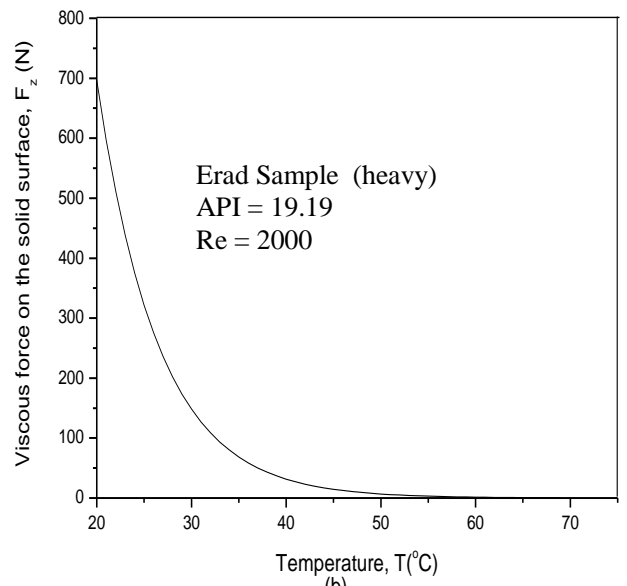

(b)

Figure 9. The viscous force, $F_{\mathrm{z}}$, on the walls of the annulus as a function of temperature at Reynolds number 2000 for: (9a) light (Zal-41) and (9b) heavy (Erad) crude oils.

Owing to the presence of the net pressure $\Delta p(T)$ in the viscous force $F_{z}$, Figure 9 follows the profile of $\Delta p(T)$ as shown in figure 7.

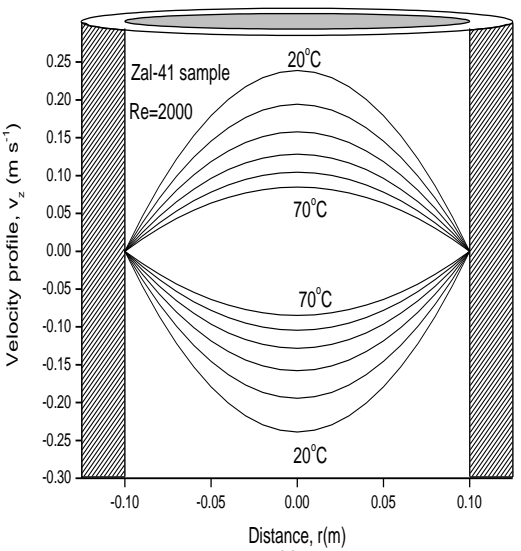

(a)

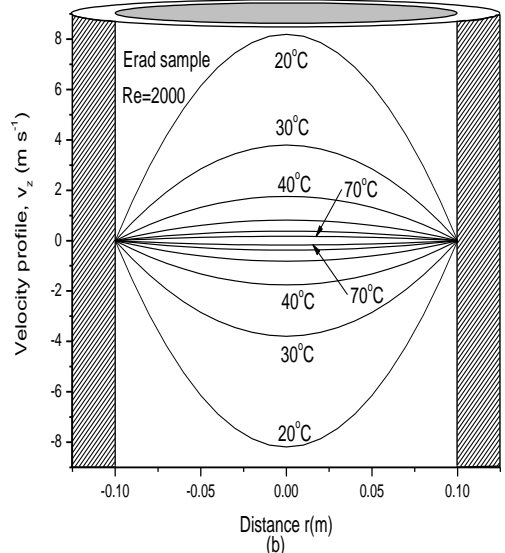

(b)

Figure 10. The velocity profile at various temperatures as a function of the distance, $r$ from the center of the cylinder towards its surface for (10a) Zal-41 sample and (10b) Erad sample. 


\section{DYNAMICAL PROPERTIES OF OMANI CRUDE OILS}

\subsection{Vertical cylinder}

The calculated results on dynamical properties of two extreme samples, namely Zal-41 [lightest] and Erad [heaviest] samples through cylindrical tubes are presented and discussed in this section. The length and radius of the cylinder are $30 \mathrm{~m}$ and $0.1 \mathrm{~m}$ respectively.

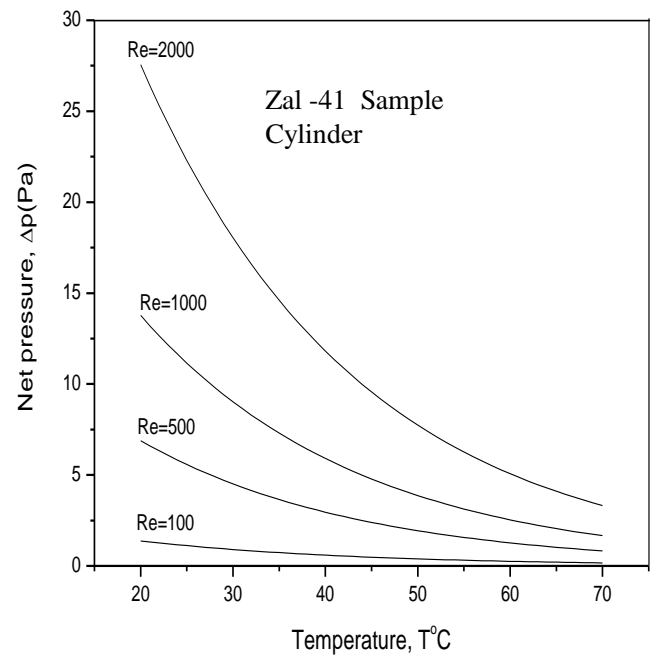

(a)

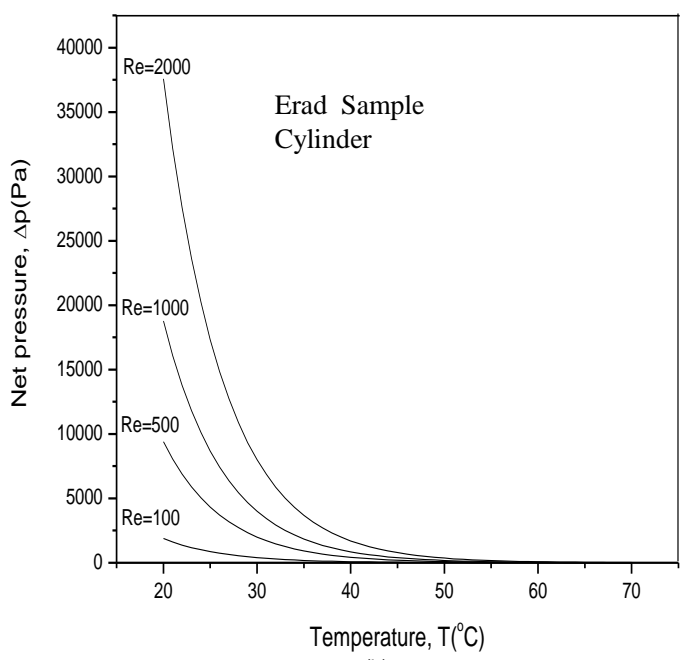

(b)

Figure 11. The net pressure on the fluid samples in a cylinder as function of temperature at various Reynolds number $R e$ values for: (11a) a Zal-41 sample and (11b) an Erad sample.

Figures 10 (a-b) show plots of the net pressure values as a function of temperature for upward laminar flow $(\mathrm{Re}=2000)$ of Zal-41 and Erad crude oil samples through a cylindrical pipe. The pipe is $30 \mathrm{~m}$ long and has a radius of $10 \mathrm{~cm}$. The net pressure is quite high at low temperatures and decreases sharply up to about $40^{\circ} \mathrm{C}$ after which it slowly reduces to zero at higher temperatures. The heavy crude oil (Erad sample) which has low API value (19.19) shows a sharp decrease in net pressure in comparison with the light crude oil (Zal-41 sample) having a high API value of 40.89. The shape of the curves can be predicted from equation (11) which involves the viscosity term, $\mu^{2}$ in its numerator indicating that this term decreases more rapidly than the density, $\rho$ in the denominator. The zero net pressure means that the applied pressure, $p_{\mathrm{a}}$ should equal the pressure $(\rho g L)$ due to the column of liquid in the cylinder. Since $\rho$ decreases with increasing temperature, the applied pressure should decrease as well in order to balance the liquid column pressure for no flow through the pipe. $p_{\mathrm{a}}$ in general will decrease with increasing temperature for a fixed Reynolds number. Owing to the presence of the net pressure $\Delta p(T)$ in the viscous force $F_{\mathrm{z}}$, Figure 13 follows the profile of $\Delta p(T)$ as shown in Figure 11.

\section{Conclusions}

We have investigated a few dynamical properties of some Omani crude oils through an annulus and a cylindrical pipe of fixed dimensions, in terms of the measured density and viscosity of these samples at various temperatures. The underlying methodology involves a simple model of fluid dynamics based on Newtonian approximation applied to laminar flow. 


\section{SAYYADUL ARAFIN and S.M. MUJIBUR RAHMAN.}

The measured density and viscosity respectively follow the equations: $\rho(t)=\rho_{o}+m\left(t-t_{r}\right)$ and $\mu(t)=\mu_{o}^{\left(\frac{-t}{E}\right)}$ within the selected range of temperatures. Subsequently we have studied the dynamical properties of these samples through an annulus and a finite-dimension cylindrical tube.

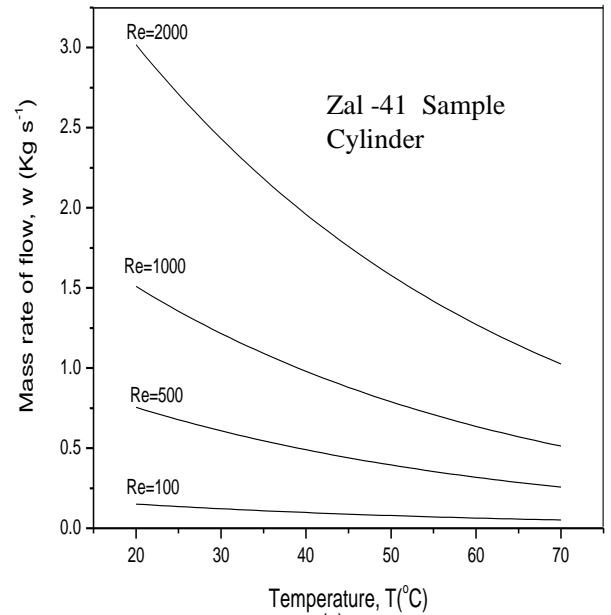

(a)

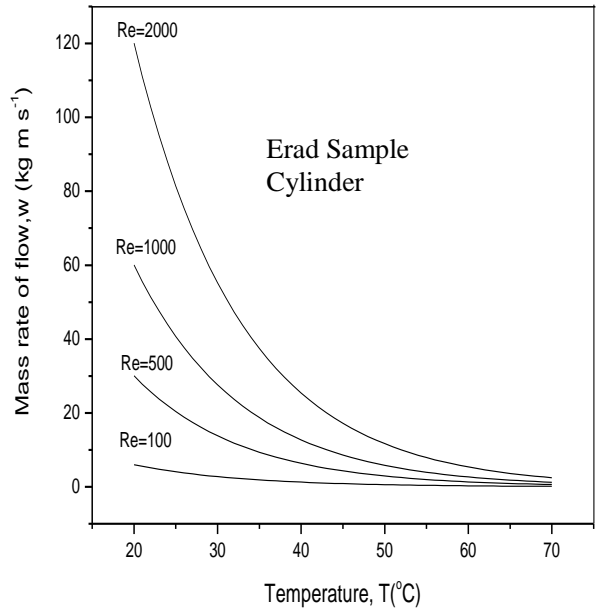

(b)

Figure 12. The mass rate of flow $w$ through a cylindrical pipe as a function of temperature at various Reynolds number $R e$ values for: (12a) a light Zal-41 sample and (12b) a heavy Erad sample.

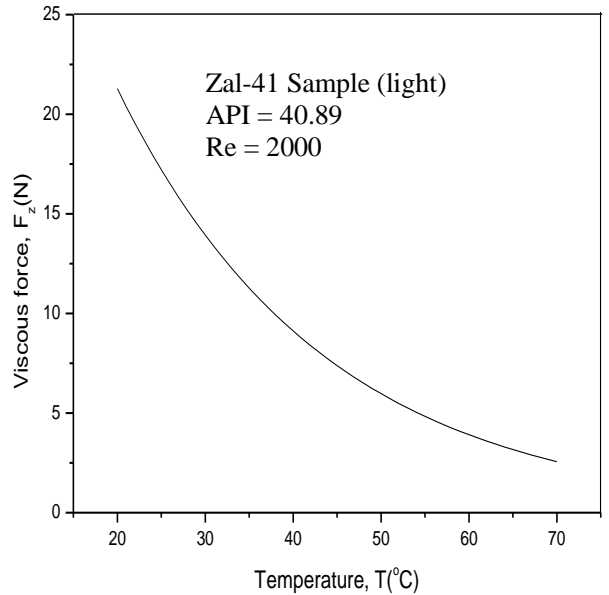

(a)

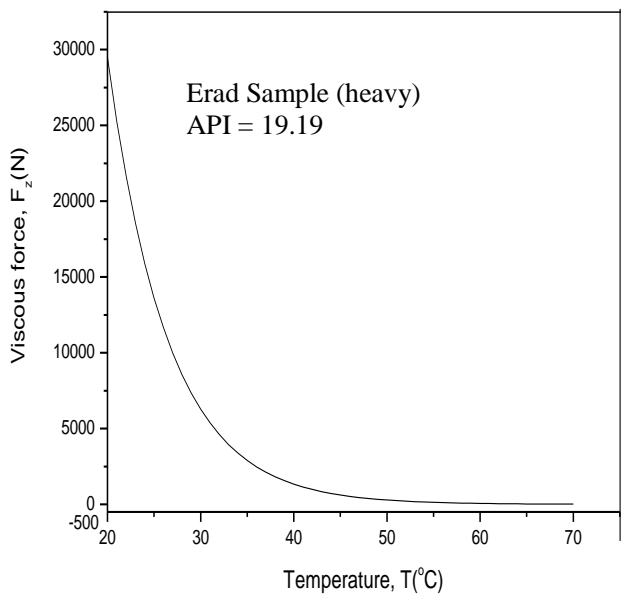

(b)

Figure 13. The viscous force $F_{\mathrm{z}}$ on the walls of the cylinder as a function of temperature at Reynolds number 2000 for: (13a) light (Zal-41) and (13b) heavy (Erad) crude oils. 


\section{DYNAMICAL PROPERTIES OF OMANI CRUDE OILS}

The investigation of the dynamical properties using simplified models in conjunction with the measured viscosity data sheds some light on the Omani crude oil properties. However, we would like to make the following critical remarks in light of the presented findings:

(a) The concept of momentum balance used in the formalism is merely an approximation applicable for ideal Newtonian liquid. Any non-Newtonian fluid has indeed a non-zero term on the right hand side of the momentum-balance equation. Consideration of non-Newtonian approximation will certainly necessitate the usage of the non-linear form of the Navier-Stokes equation. Thus it is apparent that the present approximation yields qualitative results only.

(b) The dynamic properties reported in the article have been studied by using simplified models and geometry that have neglected wall and end effects, coarseness and non-linearity. These effects should be looked at using more realistic models and geometry within the realm of a non-Newtonian fluid model.

(c) The Omani crude oils investigated have been treated as isotropic fluids without any inherent phase separation or segregation among components. These effects might be relevant to any investigation of dynamic properties. Presently we are working on a project considering the above points.

\section{References}

ADECHY, D. and ISSA, R.I., 2004. Modeling of Annular Flow Through Pipes and T-junctions. Computers and Fluids, 33: 289-313.

AHMED, T. 2000. Reservoir Engineering Handbook. Gulf Publishing, Houston,TX.

ARAFIN, S., AL-HABSI, N. and RAHMAN, S.M.M., 2011. Transport Properties and Model-based Dynamical Properties of Omani Crude Oils. Arab J. Geosci. [Springer], DOI 10.1007/s/12517-011-0301-z.

BAI, R., KELKAR, K., and JOSEPH, D.D., 1996. Direct Simulation of Interfacial Waves in a High-viscosityRatio and Axisymmetric Core-Annular Flow, J. Fluid Mech, 327: 1-34.

BATZLE, M. and WANG, Z. 1992. Seismic Properties of Pore Fluids. Geophysics 57: 1396-1408.

BIRD, R.B., STEWART, W.E. and LIGHTFOOT, E.N., 2002. Transport Phenomena. John Wiley \& Sons, New York.

GEORGE, A.K., ARAFIN, S., SINGH, R.N. and CARBONI, C., 2006. A Correlation Between Surface, Transport and Thermo-elastic Properties of Liquid Hydrocarbon: An Experimental Investigation. J. Phys: Condens. Matter 18: 3691-3701.

HO, W.S. and Li, N.N. 1994. Core-annular Flow of Liquid Membrane Emulsion. AIChE J., 40: 1961-1968.

LI H.-B., WU C. and ZHENG. Y-G., 2004. Plane Flow Model of Non-Newtonian Turbulent Stratified Flow in Wells and Pipes. J. Pet. Sci. \& Eng. 44: 223-229.

NASERI, A., NIKAZAR, M., MOUSAVI, S.A. and DEGHANI, A.A.M., 2005. A Correlation Approach for Prediction of Crude Oil Viscosities. J. Pet. Sci. \& Eng. 47: 163-174.

PRADA, J.W.V. and BANNWART, A.C., 2001. Modeling of Vertical Core-annular Flows and Application to Heavy Oil Production. Transaction of the ASME, 123: 194-199.

SHERTOK, J.T. 1975. Velocity Profiles in Core-annular Flow using a Laser-Doppler Velocimeter. Ph.D. Thesis, Princeton University, Department of Chemical Engineering, Princeton, NJ.

SHIOTSU, M. and HAMA, K., 2000. Film Boiling Heat Transfer from a Vertical Cylinder in Forced Flow of Liquids Under Saturated and Sub-cooled Conditions at Pressures. Nucl. Engg. Design, 200: 23-38.

Received: 30 October 2011

Accepted: 20 November 2011 